\title{
The cytotoxic effect of Baeckea frustescens extracts in eliminating hypoxic breast cancer cells
}

\author{
S. H. Shahruzaman ${ }^{1}$, F. Z. Yusof ${ }^{1}$, S. Maniam² ${ }^{2}$ S. Fakurazi ${ }^{1}$ and S. Maniam ${ }^{*}$
}

\begin{abstract}
Background: Adaptive metabolic response towards a low oxygen environment is essential to maintain rapid tumour proliferation and progression. The vascular network that surrounds the tumour develops an intermittent hypoxic condition and stimulates hypoxia-inducing factors. Baeckea frutescens is used in traditional medicine and known to possess antibacterial and cytoprotective properties. In this study, the cytotoxic effect of $B$. frutescens leaves and branches extracts against hypoxic human breast cancer (MCF-7) was investigated.
\end{abstract}

Method: The extracts were prepared using Soxhlet apparatus for ethanol and hexane extracts while the water extracts were freeze-dried. In vitro cytotoxic activities of $B$. frutescens extracts of various concentrations (20 to 160 $\mu \mathrm{g} / \mathrm{mL}$ ) at 24, 48, and 72 hours time points were studied using MTT in chemically induced hypoxic condition and in 3-dimensional in vitro cell culture system. An initial characterisation of B. frutescens extracts was carried out using Fourier-transform Infrared- Attenuated Total Reflection (FTIR-ATR) to determine the presence of functional groups.

Results: All leaf extracts except for water showed IC50 values ranging from $23-158 \mu \mathrm{g} / \mathrm{mL}$. Hexane extract showed the lowest IC50 value $(23 \mu \mathrm{g} / \mathrm{mL})$, indicating its potent cytotoxic activity. Among the branch extracts, only the $70 \%$ ethanolic extract (B70) showed an IC50 value. The hexane leaf extract tested on 3- dimensional cultured cells showed an IC50 value of $17.2 \mu \mathrm{g} / \mathrm{mL}$. The FTIR-ATR spectroscopy analysis identified various characteristic peak values with different functional groups such as alcohol, alkenes, alkynes, carbonyl, aromatic rings, ethers, ester, and carboxylic acids. Interestingly, the FTIR-ATR spectra report a complex and unique profile of the hexane extract, which warrants further investigation.

Conclusion: Adaptation of tumour cells to hypoxia significantly contributes to the aggressiveness and chemoresistance of different tumours. The identification of $B$. frutescens and its possible role in eliminating breast cancer cells in hypoxic conditions defines a new role of natural product that can be utilised as an effective agent that regulates metabolic reprogramming in breast cancer.

Keywords: Baeckea frutescens, hypoxia, breast cancer, apoptosis, 3-dimensional cell culture

\footnotetext{
*Correspondence: sandra@upm.edu.my

1 Department of Human Anatomy, Faculty of Medicine and Health

Sciences, Universiti Putra Malaysia, 43400 UPM, Serdang, Selangor Darul

Ehsan, Malaysia

Full list of author information is available at the end of the article
} original author(s) and the source, provide a link to the Creative Commons licence, and indicate if changes were made. The images or other third party material in this article are included in the article's Creative Commons licence, unless indicated otherwise in a credit line to the material. If material is not included in the article's Creative Commons licence and your intended use is not permitted by statutory regulation or exceeds the permitted use, you will need to obtain permission directly from the copyright holder. To view a copy of this licence, visit http://creativecommons.org/licenses/by/4.0/. The Creative Commons Public Domain Dedication waiver (http://creativeco mmons.org/publicdomain/zero/1.0/) applies to the data made available in this article, unless otherwise stated in a credit line to the data. 


\section{Introduction}

It is estimated that 18.1 million new cases and 9.6 million cancer deaths worldwide in 2018 and breast cancer is being the most commonly diagnosed and leading cause of death among females [1]. Studies have shown $5-10 \%$ of newly diagnosed breast cancer patients present with metastasized tumours [2] and the risk of developing metastatic disease following primary tumour resection and adjuvant therapy [3]. Metastases in cancer is the central feature of malignancy and one key causes of failure in cancer therapy [4]. Metastatic progression in tumorigenesis is initiated by genes involved in energy production, angiogenesis, tissue remodelling, enhance cell motility, matrix degradation, and epithelial-to-mesenchymal transition [5]. These genes trigger low aggressive cancer cells to invade surrounding tissues, attract supportive stroma, disperse cancer cells, and infiltrate distant metastatic niches [3]. Hyper-proliferative cancer cells outgrow their surrounding vascular network developing an intermittent hypoxic condition and stimulate hypoxia-inducing factor (HIF) [6].

As cancer progresses, cancer cells exploit and adapt their surroundings to facilitate inappropriate growth, angiogenesis, invasiveness, and ultimately metastasize $[7,8]$. The development of a tumour requires an intricate interaction between the spatial organization of the cell surface receptors and the surrounding microenvironment. Cell-based assays have been an important pillar for the drug discovery process and rely on the availability of a versatile platform that is able to recapitulate the pathophysiological features of a native tumour and its microenvironment [9].

All solid tumours contain areas that are well oxygenated, poorly oxygenated, and necrotic cells [10]. The tumour microenvironment can be chemically mimicked or the use of an in vitro culture systems that can recapitulate the relevant aspects of solid tumours. Recently, a growing body of evidence has suggested that threedimensional (3D) culture systems, in contrast to 2D, are more reflective of in vivo cellular responses. 3D culture systems have the ability to recapitulate the tumour-like environments. Hence, it provides more accurate and reproducible toxicity information for early stage drug discovery. In this study, the hypoxic environment was mimicked using dimethyloxalylglycine (DMOG), a synthetic analogue of $\alpha$-ketoglutarate, commonly used to induce HIF signalling and inhibit oxygen consumption in cancer cell lines was used to induce a hypoxic environment [11] as well as 3D culture system.

Baeckea frutescens of the family Myrtaceae and subfamily Myrtoideae are found in Malaysia, Indonesia, Southern China, and Australia [12, 13]. The bioactive constituents of $B$. frutescens were shown to possess various properties such as antibacterial [14-16]], antioxidant [17], anti- inflammatory [18] and LDL-oxidation inhibitor in arteriosclerosis [19] as well as some traditional medicine values in treating influenza, dysentery and measles [20].

Our lab has previously explored the cytotoxicity of $B$. frutescens leaves [21] and branch [22] extracts on human breast cancer cells (MCF-7). The extracts showed selective cytotoxicity with $\mathrm{IC}_{50}$ of less than $50 \mu \mathrm{g} / \mathrm{mL}$ and inhibited glucose consumption as early as 24 hours after treatment. Paving our way in further exploring the anticancer properties of $B$. frutescens, this study aims to investigate the cytotoxicity effect of $B$. frutescens leaves and branch extracts on hypoxic MCF-7 cells. This is the first study to report on the cytotoxicity effect of $B$. frutescens in hypoxic condition.

\section{Materials and Methods Extracts preparation}

B. frutescens or Cucur Atap was collected from Forest Research Institute Malaysia (FRIM) Research Station in Setiu, Terengganu upon permission from the local district. Collected plant specimens were authenticated by a botanist, Dr Shamsul Khamis at Institute of Bioscience, Universiti Putra Malaysia. A voucher specimen was deposited with the accession number: KLU 47909 at the herbarium of the Institute of Bioscience, Universiti Putra Malaysia. The leaves and branches of $B$. frutescens were air- dried under shade for 7 days and were pulverized into coarse powder. The coarse powder was extracted using hexane, ethanol, and water as previously described by Shahruzaman et al. [21]. Briefly, for ethanol extracts, $111 \mathrm{~g}, 142 \mathrm{~g}$, and $200 \mathrm{~g}$ of coarse powder were weighed and extracted in $5 \mathrm{l}$ of ethanol to obtain 90,70 , and 50 , respectively. A final concentration of $100 \mu \mathrm{g} / \mathrm{ml}$ in the media was used for subsequent experiments. The experimental research conducted in this study was complied with the guidelines from Universiti Putra Malaysia. .

\section{Cell lines human}

MCF-7 breast carcinoma cells (ATCC, USA) were grown in DMEM supplemented with $100 \mu \mathrm{g} / \mathrm{mL}$ streptomycin, $100 \mathrm{IU} / \mathrm{mL}$ penicillin, and $10 \%$ fetal bovine serum (FBS) (Sigma-Aldrich, USA). Cells were maintained at $37^{\circ} \mathrm{C}$ in $5 \% \mathrm{CO}_{2}$.

\section{Inducing hypoxia}

Dimethyloxalylglycine (DMOG), a synthetic analogue of $\alpha$-ketoglutarate, commonly used to induce HIF signalling and inhibit oxygen $\left(\mathrm{O}_{2}\right)$ consumption in cancer cell lines was used to induce a hypoxic environment [11]. MCF-7 human breast cancer cells were plated into 96-well microplates and was treated with DMOG at various 


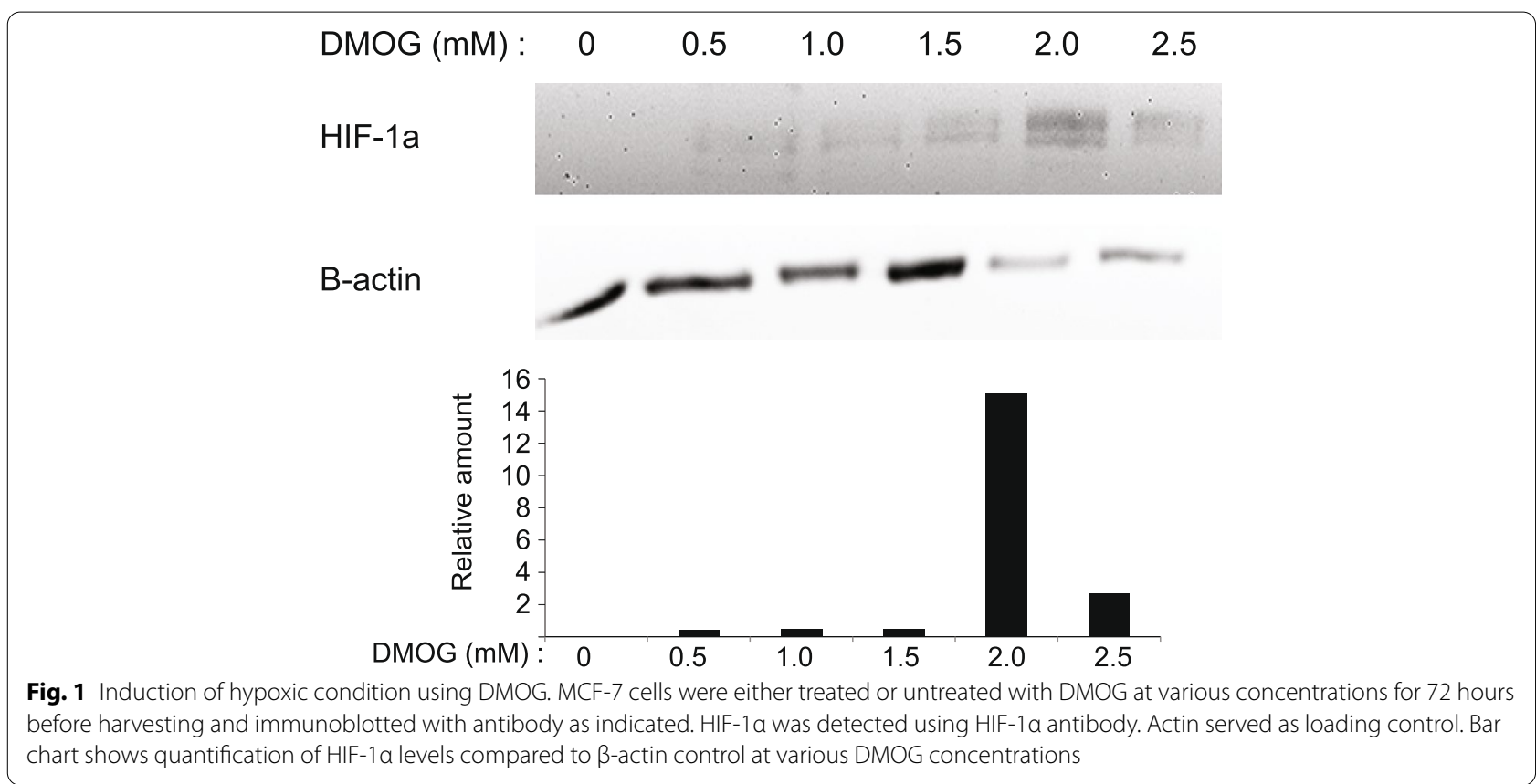

concentration $(0-2.5 \mathrm{mM})$ for 72 hours at $37^{\circ} \mathrm{C}$ in $5 \%$ $\mathrm{CO}_{2}$.

\section{Western blot}

Cells were lysed with TNN lysis buffer containing protease inhibitor cocktail (leupeptin, pepstatin A, aprotinin, bestatin, AEBSF-HCl, E-64). Equal amounts of proteins were separated by SDS-PAGE and transferred to a nitrocellulose membrane. After blocking, the blots were incubated with primary antibodies HIF-1 $\alpha$ (1:1000) (BD Pharmagen, Oxford,UK) and $\beta$-actin (1:1000) (Santa Cruz, Heidelberg, Germany). After washing and incubating with mouse secondary antibody (1:10000) (Dako, California, USA), the blots were visualised using enhanced chemiluminescent Western Blotting detection kit (Pierce, ThermoFisher Scientific, USA). The image obtained was analysed using Gene Tools analysis software (Syngene, UK).

\section{Cell viability assay}

MCF-7 human breast cancer cells were plated into 96-well microplates at an initial seeding density of $2 \times$ $10^{3}$ cells per well in a volume of $200 \mu \mathrm{l}$ of culture media. Cells were cultured at $37^{\circ} \mathrm{C}$ in $5 \% \mathrm{CO}_{2}$ overnight to allow attachment on to the wells. Hypoxic condition was induced with DMOG (Cayman, USA) with a final concentration of $2.0 \mathrm{mM}$ overnight and then treated with increasing concentration ( 20 to and $160 \mu \mathrm{g} / \mathrm{mL}$ ) of $B$. frutescens extracts for 24,48 and 72 hours.

The MTT assay was conducted as previously described [21]. Briefly, $30 \mu \mathrm{l}$ of MTT/Phosphate buffered saline (PBS) (Amresco, USA) solution was added into each well and incubated for 4 hours in dark. The formazan grain was dissolved in DMSO (Amresco, USA) and the absorbance which corresponds to viable cells was measured at $570 \mathrm{~nm}$ (Wavelength range: $550-600 \mathrm{~nm}$ ) by using an ELISA plate reader (Tecan 200, Switzerland).

\section{3-dimensional cells}

MCF-7 cells were seeded on VECELL G-plates (Geneion-bio, Malaysia) at a density of $2 \times 10^{3}$ cells and cultured in DMEM supplemented with 10\% FBS, $100 \mu \mathrm{g} /$ $\mathrm{mL}$ streptomycin and $100 \mathrm{IU} / \mathrm{mL}$ penicillin at $37^{\circ} \mathrm{C}$ in a humidified atmosphere containing $5 \% \mathrm{CO}_{2}$. The cells were grown for 72 hours until spheroid were formed (Figure S1). The spheroids were treated with the indicated drugs for 72 hours.

\section{(See figure on next page.)}

Fig. 2 Effects of B. frutescens leaves extracts on MCF-7 cell viability in hypoxic condition. Cytotoxicity was determined using cell viability assay and the IC50 value calculated as half maximal percentage of cell viability inhibition is indicated by the red horizontal line. Hypoxic condition was induced in MCF-7 cells with 2.0 mM of DMOG and incubated with either (a) hexane, (b) $L 90,(\mathbf{c}) L 70,(\mathbf{d}) L 50$ or (e) water extract of $B$. frutescens leaves or (f) etoposide, which served as positive control for 48 (left panels) or 72 (right panels) hours. Data is expressed as mean \pm standard error mean based on six independent experiments with triplicate wells for each concentration 
48 hours

A.

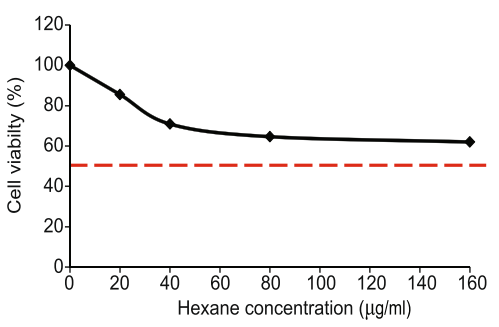

B.

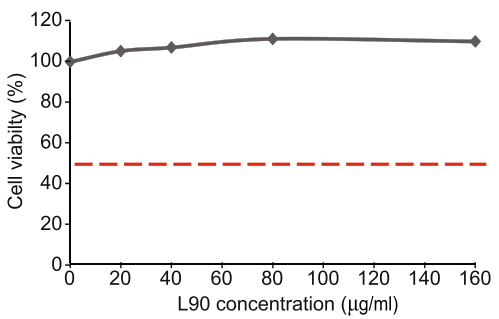

C.

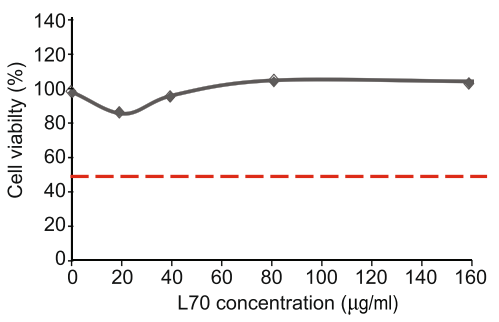

D.

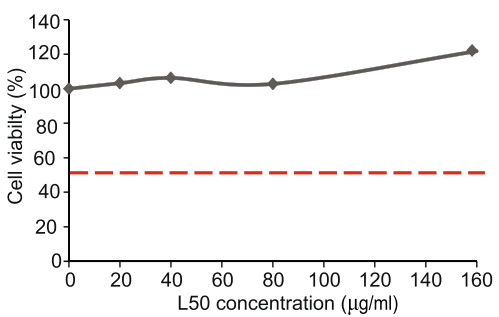

E.

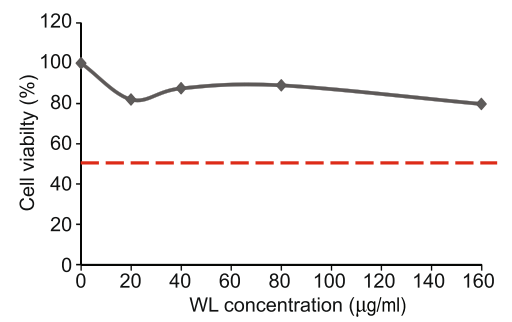

F.

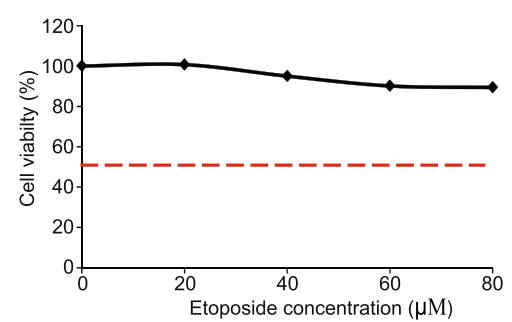

72 hours
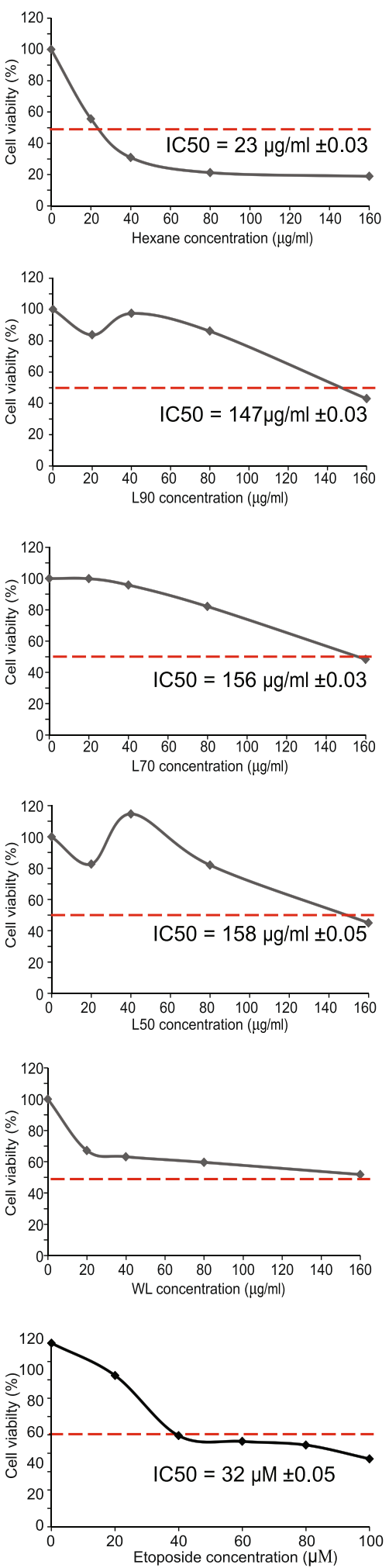

Fig. 2 (See legend on previous page.) 


\section{Fourier transform infrared spectroscopy attenuated total reflection (FTIR-ATR)}

FTIR-ATR was used to determine the functional group in the extracts. Nine B. frutescens extracts were tested at room temperature in the full scan range between $450-4000 \mathrm{~cm}^{-1}$ to determine the functional groups in the extract [23].

\section{Statistical analysis}

Data were expressed as mean \pm SEM (Standard Error of the Mean). SPSS (version 20) statistical software was used for the analysis of data. Data were analysed using one way analysis of variance (ANOVA) followed by Bonferroni post-hoc test and $\mathrm{p}<0.05$ was taken as the level of significance.

\section{Results and Discussion}

Adaptive metabolic response towards a low oxygen environment is essential to maintain rapid tumour proliferation and progression [24]. The vascular network that surrounds the tumour develops an intermittent hypoxic condition and stimulates HIF [25]. HIF is a key regulator responsible for the induction of genes that facilitate the adaptation and survival of cells and the whole organism from normoxia $\left(\sim 21 \% \mathrm{O}_{2}\right)$ to hypoxia $\left(\sim 0.5 \% \mathrm{O}_{2}\right)$ [26]. The stabilization of HIF is a hallmark of hypoxia and results in global transcriptional changes in gene expression, including genes with roles in promoting tumour progression, angiogenesis, metastasis, iron metabolism, glucose metabolism, cell proliferation and survival [27, 28]. Overexpression of HIF-1 has been found in various cancers, and targeting HIF-1 could represent a novel approach to cancer therapy. Adaptation of tumour cells to hypoxia induced HIF-1 significantly contributes to the aggressiveness and chemoresistance of different tumours. HIF-1 plays a central role in tumour pathology and is a target for treatment and therapy [29, 30]. A number of drugs target HIF inhibition which includes EZN-2208 [31], PX-478 [32]. The discovery of HIF-1 has led to an improved understanding of the molecular link between hypoxia and deregulated glucose metabolism [33]. In this study, the hypoxic condition was mimicked by chemically inducing HIF-1 expression or by using a 3D culture system.
In this study, the hypoxic environment was mimicked using dimethyloxalylglycine (DMOG) to induce a hypoxic environment. An initial increase of HIF was observed at $0.5 \mathrm{mM}$. However, at $2.0 \mathrm{mM}$ showed an increased HIF expression and this concentration of DMOG was chosen for subsequent experiments (Fig. 1). This method is inexpensive compared with the hypoxic chamber. Hypoxic cancer cells are known to be resistant to radiotherapy and some conventional chemotherapy [34]. The hypoxic microenvironment induces adaptive changes to tumour cell metabolism and can further alter the local microenvironment [35].

The methanolic derivatives from $B$. frutescens were shown to exhibit cytotoxic activity against leukaemic cells [36], human lung, pancreatic, and breast cancer cells [15]. Previously, we have measured the cytotoxic activity of hexane, water and ethanolic $B$. frutescens extracts $(0-160 \mu \mathrm{g} / \mathrm{ml})$ from leaves against MCF-7 cells for 24,48 and $72 \mathrm{~h}$ in normoxic condition. It was noted that hexane extract of $B$. frutescens leaves possess selective cytotoxic activity and modulate glucose uptake in breast cancer cells [21, 22]. To our knowledge, this is the first report describing the cytotoxic activity of $B$. frutescens extracts against MCF-7 cells in hypoxic condition.

Cytotoxic activities of nine B. frutescens extracts from leaves and branches were tested against MCF-7 cell lines for 24,48 , and 72 hours in hypoxic condition. Etoposide was used as a positive control. After 24 hours (data not shown) and $48 \mathrm{~h}$ of treatment, $\mathrm{IC}_{50}$ values of these extracts were unable to determine (left panel, Figs. 2 and 3). However, after 72 hours of treatment, all B. frutescens leaves extracts except WL showed cytotoxic activity (Fig. 2). The $\mathrm{IC}_{50}$ values of L90, L70 and L50 were higher than $100 \mu \mathrm{g} / \mathrm{mL}$. Hexane extract has the most potent with $\mathrm{IC}_{50}$ value of $23 \mu \mathrm{g} / \mathrm{mL}$. Out of the four branch extracts tested, only B70 showed cytotoxic activity with $\mathrm{IC}_{50}$ value of $150 \mu \mathrm{g} / \mathrm{mL}$ (Fig. 3). The $\mathrm{IC}_{50}$ values of $B$. frutescens extracts in hypoxic conditions were indicated in Figs. 2 and 3.One potent extract from the branches (B70) and leaves (hexane) were chosen to be tested in the 3D in vitro culture system. Growing body of evidence has suggested that 3D culture systems represent more accurately of the actual tumour microenvironment. Hence, the 3D model-based assays serve as one of the key tools

\footnotetext{
(See figure on next page.)

Fig. 3 Effects of $B$. frutescens branches extracts on MCF-7 cell viability in hypoxic condition. Cytotoxicity was determined using cell viability assay and the IC50 value calculated as half maximal percentage of cell viability inhibition is indicated by the red horizontal line. Hypoxic condition was induced in MCF-7 cells with 2.0 mM of DMOG and incubated with either (a) WB, (b) B90, (c) B70 or (d) B50 of B. frutescens branches or (f) etoposide, which served as positive control for 48 (left panels) or 72 (right panels) hours. Data is expressed as mean \pm standard error mean based on six independent experiments with triplicate wells for each concentration
} 
48 hours

A.

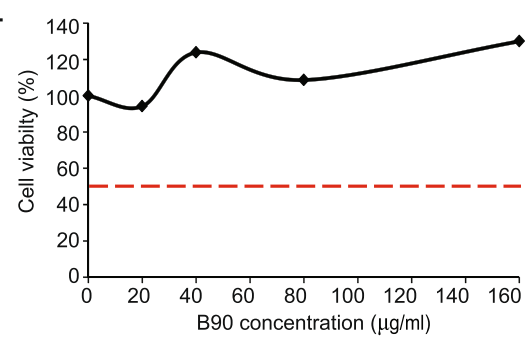

B.

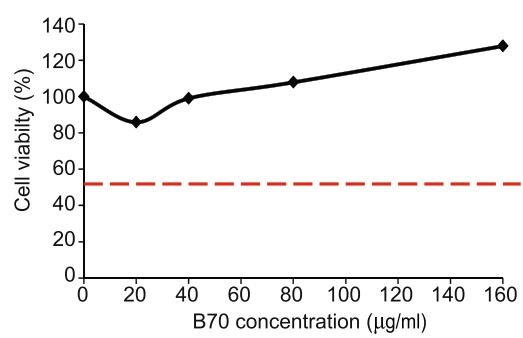

C.

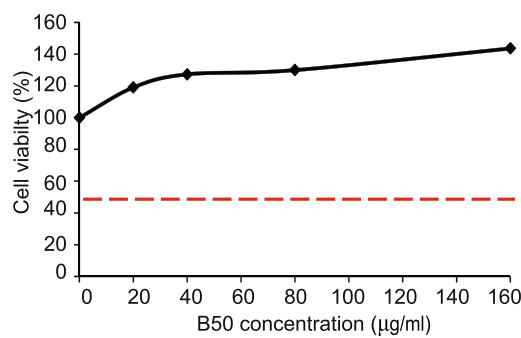

D.

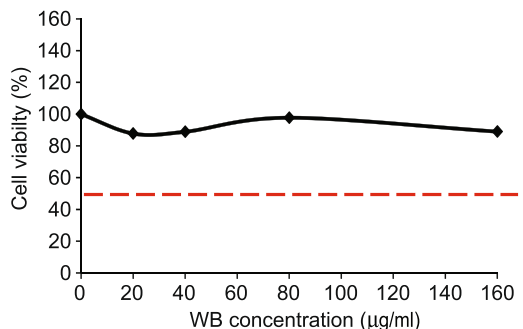

E.

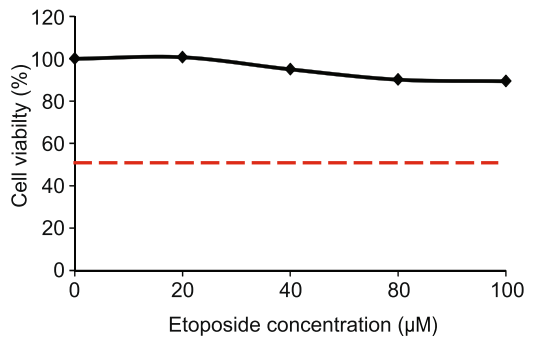

72 hours
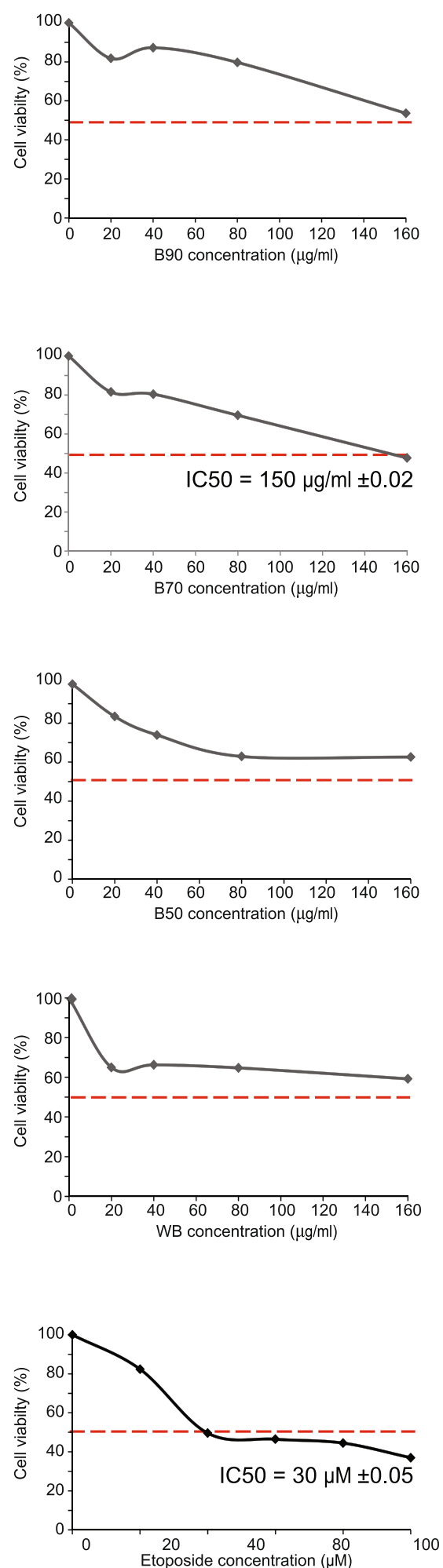

Fig. 3 (See legend on previous page.) 
A.

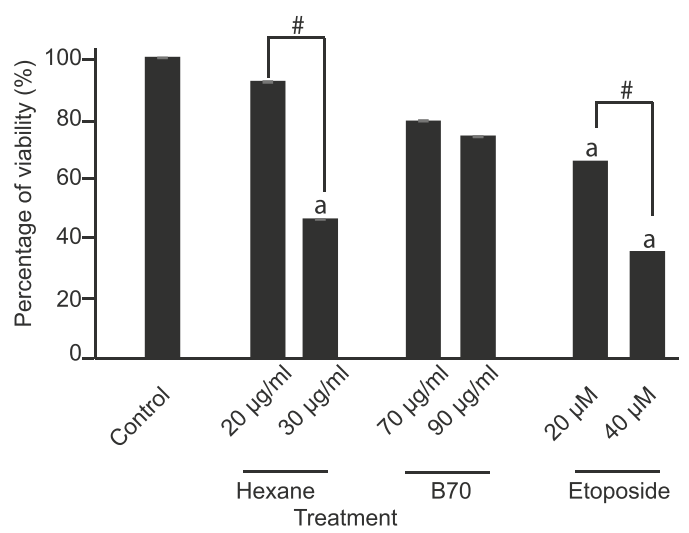

B.

\begin{tabular}{cccc}
\hline & Hexane & B70 & Etoposide \\
\hline 3D & $17.2 \mu \mathrm{g} / \mathrm{ml} \pm 0.325$ & ND & $29.8 \mu \mathrm{M}$ \\
2D & $23 \mu \mathrm{g} / \mathrm{ml} \pm 0.03$ & $150 \mu \mathrm{g} / \mathrm{ml} \pm 0.03$ & $32 \mu \mathrm{M}$
\end{tabular}

Fig. 4 Effects of selective B. frutescens extracts on 3-Dimensional cell viability. Cytotoxicity was determined using cell viability assay and the IC50 value calculated using 3D culture system. MCF-7 cells were either untreated or treated with hexane, B70 or etoposide for 72 hours at indicated concentrations (A). Etoposide served as positive control and DMSO was used as vehicle control. IC50 value obtained from the 3D in vitro system and chemically induced hypoxic condition (2D) were compared (B). p $<0.05$. a indicate statistically significant compared to control and \# indicate statistically significant within group. Data are displayed as mean \pm SD

to assess the potential efficacy of these compounds. Hexane extract at its highest concentration and etoposide at all concentration showed significantly lower cell viability compared to the vehicle control in the 3D in vitro system. No significant changes were observed in B70 (Fig. 4a).

Both hexane and etoposide showed lower $\mathrm{IC}_{50}$ value in the 3D in vitro system compared to the chemically induced hypoxia (Fig. 4b). All solid tumours contain areas that are well oxygenated, poorly oxygenated, and necrotic cells [10]. The tumour microenvironment can be chemically mimicked or the use of an in vitro culture systems that can recapitulate the relevant aspects of solid tumours. The use of 3D culture systems in contrast to 2D were shown to be more reflective of in vivo cellular responses. 3D culture systems have the ability to recapitulate a tumour-like environment. Hence, it provides more accurate and reproducible toxicity information for early stage drug discovery.

Interestingly, the $\mathrm{IC}_{50}$ value obtained in normoxic condition $(17 \mu \mathrm{g} / \mathrm{mL})$ as previously reported [21] were much lower compared to the values obtained in hypoxic condition. Furthermore, it was noted that $\mathrm{IC}_{50}$ of the hexane extract in normoxic condition was obtained as early as 48 hours [21] which is a shorter duration compared to the $\mathrm{IC}_{50}$ obtained in hypoxic condition (72 hours). This is most likely due to aggressive growth stimulated by hypoxic conditions, hence a higher amount of extract and longer time are required to suppress cell viability. A typical tumour microenvironment consists of fibroblasts, myofibroblasts, neuroendocrine cells, adipose cells, immune and inflammatory cells, blood and lymphatic vascular networks, and the extracellular matrix [37]. The lack of oxygenation results in increased collagen deposition or also known as desmoplasia [38]. The dynamic function of desmoplastic stroma during tumorigenesis that supports tumour growth, progression, and recruitment, through other cellular and noncellular constituents evolves with the genetic profile changes of cancer cells $[39,40]$. Adaptation of cancer cells to a hypoxic condition leads to a more aggressive and therapeutically resistant tumour phenotype [6].

The initial characterisation of $B$. frutescens extracts of leaves and branches were carried out using FTIR- ATR to determine the presence of functional groups (Fig. 5). Taking into account that $B$. frutescens leaves and branch extracts are a combination of several molecules, their infrared spectra are complex and include a variety of bands from various functional groups. Similar spectra were obtained for the polar extracts of WB, WL, L70, L50, B50, B90 and B70. Taking B70 as an example, an intense signal at $3426 \mathrm{~cm}^{-1}$ characteristic for the stretching of O-H bond and a weak signal at 2995-2911 $\mathrm{cm}-1$, which corresponds to $\mathrm{C}-\mathrm{H}$ bond stretching were observed. In the fingerprint region, a weak signal 1654 


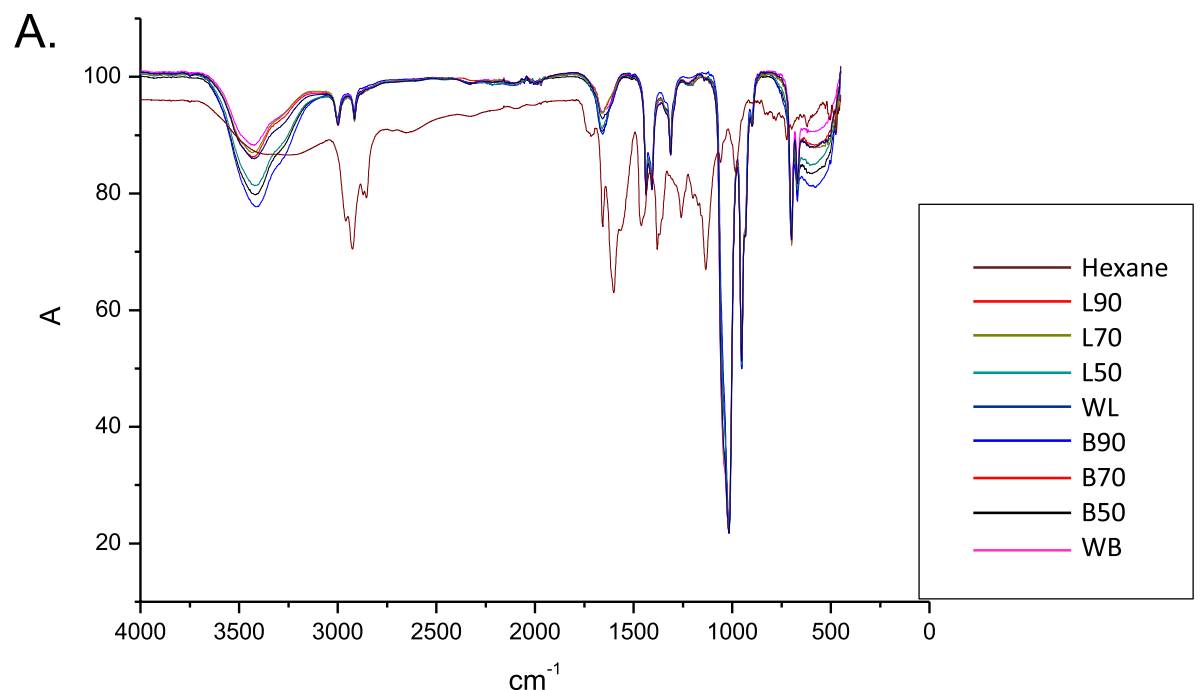

B.

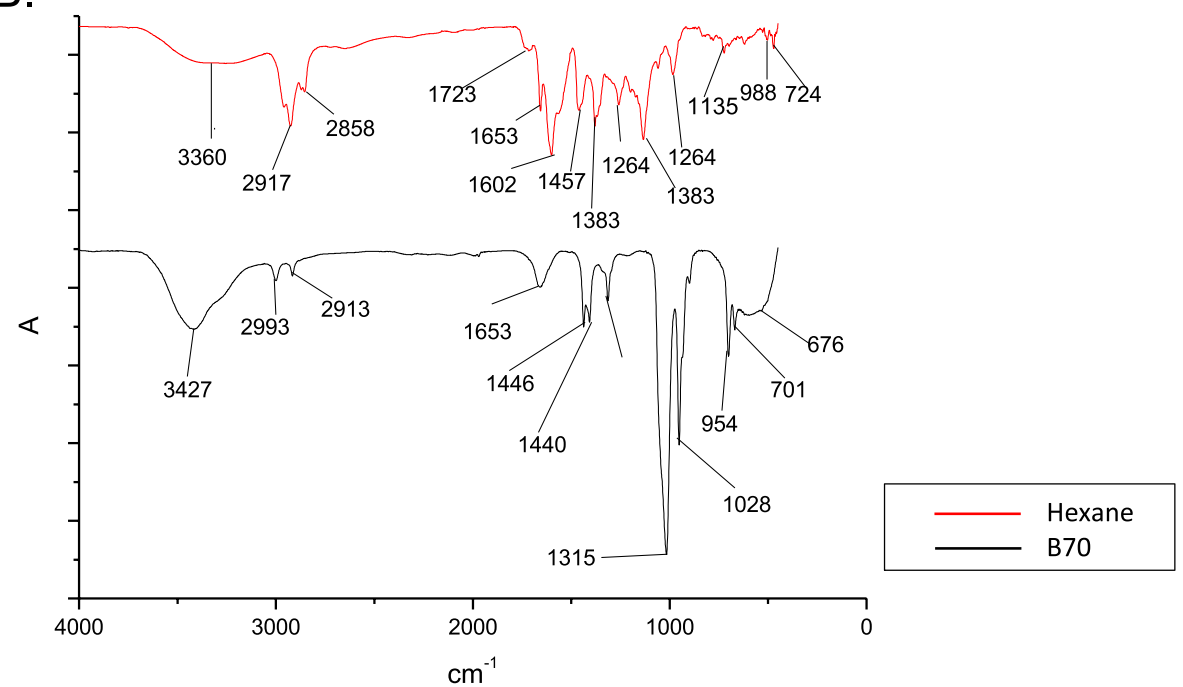

Fig. 5 FTIR-ATR spectra of $B$. frutescens extracts in the range of $450-4000 \mathrm{~cm}^{-1}$. Combined FTIR spectra of $B$. frutescens leaves and branches extracts (A). FTIR spectra of B. frutescens leaves(hexane) and branches extracts; B70 (B)

Table 1 Assignment of FTIR signals for B. frutescens leaves and branches extracts in hexane, $\mathrm{H}$ and B70

\begin{tabular}{llll}
\hline $\begin{array}{l}\text { Frequency }\left(\mathbf{c m}^{-\mathbf{1}}\right) \\
\text { HX }\end{array}$ & B70 & Type of bond & Functional group \\
\hline 2917,2858 & 3426 & $\mathrm{O}-\mathrm{H}$ & Alcohol \\
1653,1602 & 2995,2911 & $\mathrm{C}-\mathrm{H}, \mathrm{C} \equiv \mathrm{C}$ & Alkene, Alkyne \\
1457,1383 & 1654 & $\mathrm{C}=\mathrm{O}, \mathrm{C}=\mathrm{C}$ & Alkene, carbonyl \\
& 1447,1441 & $\mathrm{C}=\mathrm{C}$ & Aromatic rings \\
& 1315 & $\mathrm{C}-\mathrm{O}$ & Ether, ester or carboxylic acid \\
& 1028 & $\mathrm{C}-\mathrm{OH}$ & Secondary alcohol functional group \\
& 956 & $\mathrm{C}-\mathrm{OH}$ & Primary alcohol functional group \\
\hline
\end{tabular}


$\mathrm{cm}^{-1}$ which were assigned to $\mathrm{C}=\mathrm{C}$ or $\mathrm{C}=\mathrm{O}$ stretching and the strong signal at $1315 \mathrm{~cm}^{-1}$ were attributed to the $\mathrm{C}-\mathrm{O}$ stretching. These results indicate the characteristic presence of glycosides, several different kinds of carbonyl compounds, and flavonoids (Table 1) [20]. In the nonpolar extract, hexane, intense signals at 2917-2856 $\mathrm{cm}^{-1}$ which correspond to $\mathrm{C}-\mathrm{H}$ stretching of saturated hydrocarbons were recorded. Additionally, strong signals at 1653,1602 , and $1457 \mathrm{~cm}^{-1}$ attributed to $C=C$ and aromatic ring skeletal stretching were also observed. This extract has a significantly different infrared spectrum profile compared to the other polar extracts and has not been previously reported. Hexane being a nonpolar solvent, extracts lipophilic compounds which are known to have better uptake and absorption rate in cells compared to polar compounds. FTIR-ATR spectroscopy analysis of the hexane extract suggests that large lipophilic groups such as aliphatic chain and aromatic structures are part of the compound with no significant polar functional groups.

\section{Conclusion}

In conclusion, this study reports $B$. frutescens extracts of both branch (B70) and leaf (hexane, L90, L70, and L90) extracts are able to induce cell death in hypoxic condition. Hexane extract from the leaves was shown to induce cell death in both chemically induced hypoxic condition as well as 3D in vitro culture system. In DMOG-induced hypoxic condition, B. frutescens extracts require longer treatment time and higher concentrations to produce cytotoxic effect compared to normoxic condition. The FTIR-ATR spectroscopy analysis identified various characteristic peak values with different functional groups attributed to compounds, mainly flavonoids, chromones, branched hydrocarbons, and phloroglucinols. Further experiments are required to characterise the FTIR-ATR profile of the hexane extract. Following our previous reports, the findings in this study reiterate the potential of $B$. frutescens as an anticancer agent for breast cancer.

\footnotetext{
Abbreviations

3D: 3-dimensional; B50: B. frutescens branches prepared at the ratio of 1:50 in ethanol B70 B. frutescens branches prepared at the ratio of 1:70 in ethanol B90 B. frutescens branches prepared at the ratio of 1:90 in ethanol DMOG; : Dimethyloxalylglycine; DMEM: Dulbecco's Modified Eagle Medium DMSO; : Dimethyl sulfoxide; EGF: Epidermal growth factor; ER: Oestrogen receptor; FTIR-ATR: Fourier transform infrared spectroscopy attenuated total reflection HIF; : Hypoxia-inducing factor; IC50: Half maximal inhibitory concentration; L50: $B$. frutescens leaves were prepared at the ratio of 1:50 in ethanol L70 B. frutescens leaves were prepared at the ratio of 1:70 in ethanol L90 B. frutescens leaves were prepared at the ratio of 1:90 in ethanol MTT; : 3-(4,5-dimethylthiazol-2-yl)-2,5-diphenyltetrazolium bromide PBS Phosphate-buffered saline; WB: - B. frutescens branch water extract.
}

\section{Supplementary Information}

The online version contains supplementary material available at https://doi. org/10.1186/s12906-021-03417-9.

Additional file 1: Figure S1. Morphology of cells in 3-dimesional culture system. MCF-7 cells were cultured on VECELL G-plate for 72 hours until spheroid were observed.

\section{Acknowledgements}

We thank the Universiti Putra Malaysia (Programme Grant: Putra Grant GPIPM/2014/9445100) and (Programme Grant: Putra Grant GP/2018/9616500) for supporting this work. SHS was supported by Graduate Research Fellowship from Universiti Putra Malaysia. SHS was also supported by MyBrain program from Malaysian Ministry of Higher Education.

\section{Authors' contributions}

SHS, SF, and SM participated in the design of the research; SF and SM guided the group of researchers. SHS contributed to plant collection, identification, and extraction; SHS and FZY carried out the experiments and analysed the data under the supervision of SM, SF. SHS and SM wrote the paper; SM ${ }^{2}$ critically revised the manuscript. All authors read and approved the final manuscript.

\section{Funding}

This study is funded by Universiti Putra Malaysia (Programme Grant: Putra Grant GP- IPM/2014/9445100) as well as (Programme Grant: Putra Grant GP/2018/9616500).

\section{Availability of data and materials}

The datasets analysed during the current study are available from the corresponding author on reasonable request.

\section{Declarations}

Ethics approval and consent to participate

Not applicable

\section{Consent for publication}

Not applicable

\section{Competing interests}

The authors declare no conflict of interest.

\section{Author details}

${ }^{1}$ Department of Human Anatomy, Faculty of Medicine and Health Sciences, Universiti Putra Malaysia, 43400 UPM, Serdang, Selangor Darul Ehsan, Malaysia. ${ }^{2}$ School of Science, RMIT University, Melbourne, VIC 3001, Australia.

Received: 22 March 2021 Accepted: 20 September 2021

Published online: 01 October 2021

\section{References}

1. Bray F, Ferlay J, Soerjomataram I, Siegel RL, Torre LA, Jemal A. Global cancer statistics 2018: GLOBOCAN estimates of incidence and mortality worldwide for 36 cancers in 185 countries. CA Cancer J Clin. 2018;68:394424. https://doi.org/10.3322/caac.21492.

2. Cardoso F, Costa A, Norton L, Cameron D, Cufer T, Fallowfield L, et al. 1st International consensus guidelines for advanced breast cancer (ABC 1). Breast. 2012:21:242-52. https://doi.org/10.1016/j.breast.2012.03.003.

3. Kimbung S, Loman N, Hedenfalk I. Clinical and molecular complexity of breast cancer metastases. Seminars in Cancer Biology. 2015;35:85-95. https://doi.org/10.1016/j.semcancer.2015.08.009.

4. Fares J, Fares MY, Khachfe HH, Salhab HA, Fares Y. Molecular principles of metastasis: a hallmark of cancer revisited. Signal Transduction and Targeted Therapy. 2020;5:28. https://doi.org/10.1038/s41392-020-0134-X. 
5. Hartung F, Wang Y, Aronow B, Weber GF. A core program of gene expression characterizes cancer metastases. Oncotarget. 2017;2;8(60):102161102175. https://doi.org/10.18632/oncotarget.22240.

6. Jing $X$, Yang F, Shao C, Wei K, Xie M, Shen H, et al. Role of hypoxia in cancer therapy by regulating the tumor microenvironment. Molecular Cancer. 2019;18:57. https://doi.org/10.1186/s12943-019-1089-9.

7. Joyce JA, Pollard JW. Microenvironmental regulation of metastasis. Nature Reviews Cancer. 2009;9(4):239-52. https://doi.org/10.1038/nrc2618.

8. Chung SW, Cooper CR, Farach-Carson MC, Ogunnaike BA. A control engineering approach to understanding the TGF- $\beta$ paradox in cancer. J R Soc Interface. 2012;9(71):1389-97. https://doi.org/10.1098/rsif.2011.0799.

9. Xu X, Farach-Carson MC, Jia X. Three-dimensional in vitro tumor models for cancer research and drug evaluation. Biotechnology Advances. 2014;32(7):1256-68. https://doi.org/10.1016/j.biotechadv.2014.07.009.

10. Lequeux A, Noman MZ, Xiao M, Sauvage D, Van Moer K, Viry E, et al. Impact of hypoxic tumor microenvironment and tumor cell plasticity on the expression of immune checkpoints. Cancer Letters. 2019;458:13-20. https://doi.org/10.1016/j.canlet.2019.05.021.

11. Zhdanov AV, Okkelman IA, Collins FWJ, Melgar S, Papkovsky DB. A novel effect of DMOG on cell metabolism: Direct inhibition of mitochondrial function precedes HIF target gene expression. Biochim Biophys Acta - Bioenerg. 2015;1847(10):1254-66. https://doi.org/10.1016/j.bbabio.2015.06.016.

12. Bean AR. A revision of Baeckea (Myrtaceae) in eastern Australia, Malesia and south-east Asia. Telopea. 1997;7:245-68. https://doi.org/10.7751/ telopea19971018.

13. Ahmad NS, A. Ghani MN, Manaf Ali A, Tajudin Tuan Johari SA, Harun MH. High Performance Liquid Chromatography (HPLC) Profiling Analysis and Bioactivity of Baeckea frutescens L. (Myrtaceae). J Plant Stud. 2012;1:101. https://doi.org/10.5539/jps.v1n2p101.

14. Hwang JK, Shim JS, Chung JY. Anticariogenic activity of some tropical medicinal plants against Streptococcus mutans. Fitoterapia. 2004;75:596-8.

15. Vu TT, Kim H, Tran VK, Le Dang Q, Nguyen HT, Kim H, et al. In vitro antibacterial activity of selected medicinal plants traditionally used in Vietnam against human pathogenic bacteria. BMC Complement Altern Med. 2016;16:32. https://doi.org/10.1186/s12906-016-1007-2.

16. Razmavar S, Abdulla MA, Ismail SB, Hassandarvish P. Antibacterial Activity of Leaf Extracts of Baeckea frutescens against Methicillin-Resistant Staphylococcus aureus. Biomed Res Int. 2014;2014:1-5. https://doi.org/ 10.1155/2014/521287

17. Navanesan S, Wahab NA, Manickam S, Sim KS. Evaluation of selected biological capacities of Baeckea frutescens. BMC Complement Altern Med. 2015;15:186

18. Jia BX, Ren FX, Jia L, Chen XQ, Yang J, Wang Q. Baeckein E, a new bioactive C-methylated biflavonoid from the roots of Baeckea frutescens. Nat Prod Res. 2013:27:2069-75. https://doi.org/10.1080/14786419.2013.778852.

19. Kamiya K, Satake T. Chemical constituents of Baeckea frutescens leaves inhibit copper-induced low-density lipoprotein oxidation. Fitoterapia. 2010:81:185-9.

20. Adib AM, Jamaludin F, Kiong LS, Hashim N, Abdullah Z. Two-dimensional correlation infrared spectroscopy applied to analyzing and identifying the extracts of Baeckea frutescens medicinal materials. J Pharm Biomed Anal 2014:96:104-10.

21. Shahruzaman SH, Mustafa MF, Ramli S, Fakurazi S, Maniam S, Maniam S. The cytotoxic effect and glucose uptake modulation of Baeckea frutescens on breast cancer cells. BMC Complement Altern Med. 2019;19(1):220. https://doi.org/10.1186/s12906-019-2628-z.

22. Shahruzaman SH, Mustafa MF, Ramli S, Maniam S, Fakurazi S, Maniam S. The Cytotoxic Properties of Baeckea frutescens Branches Extracts in Eliminating Breast Cancer Cells. Evid Based Complement Altern Med. 2019;2019:1-9. https://doi.org/10.1155/2019/9607590.

23. Warren FJ, Gidley MJ, Flanagan BM. Infrared spectroscopy as a tool to characterise starch ordered structure - A joint FTIR-ATR, NMR, XRD and DSC study. Carbohydr Polym. 2016;139:35-42. https://doi.org/10.1016/j. carbpol.2015.11.066

24. Shahruzaman SH, Fakurazi S, Maniam S. Targeting energy metabolism to eliminate cancer cells. Cancer Manag Res. 2018;10:2325-35. https://doi. org/10.2147/CMAR.S167424.

25. Masoud GN, Li W. HIF-1a pathway: role, regulation and intervention for cancer therapy. Acta Pharm Sin B. 2015;5:378-89. https://doi.org/10 1016/j.apsb.2015.05.007.
26. Wang GL, Jiang BH, Rue EA, Semenza GL. Hypoxia-inducible factor 1 is a basic-helix-loop-helix-PAS heterodimer regulated by cellular $\mathrm{O} 2$ tension. Proc Natl Acad Sci. 1995;92:5510-4. https://doi.org/10.1073/pnas.92.12.5510.

27. Airley RE, Mobasheri A. Hypoxic Regulation of Glucose Transport, Anaerobic Metabolism and Angiogenesis in Cancer: Novel Pathways and Targets for Anticancer Therapeutics. Chemotherapy. 2007;53:233-56. https://doi. org/10.1159/000104457.

28. Zhang Z, Yan J, Chang Y, ShiDu Yan S, Shi H. Hypoxia Inducible Factor-1 as a Target for Neurodegenerative Diseases. Curr Med Chem. 2011;18:433543. https://doi.org/10.2174/092986711797200426.

29. Wigerup C, Påhlman S, Bexell D. Therapeutic targeting of hypoxia and hypoxia-inducible factors in cancer. Pharmacol Ther. 2016;164:152-69. https://doi.org/10.1016/j.pharmthera.2016.04.009.

30. Hong S-S, Lee H, Kim K-W. HIF-1a: a Valid Therapeutic Target for Tumor Therapy. Cancer Res Treat. 2004;36:343. https://doi.org/10.4143/crt.2004. 36.6.343.

31. Garrett CR, Bekaii-Saab TS, Ryan T, Fisher GA, Clive S, Kavan P, et al. Randomized phase 2 study of pegylated SN-38 (EZN-2208) or irinotecan plus cetuximab in patients with advanced colorectal cancer. Cancer. 2013:119:4223-30. https://doi.org/10.1002/cncr.28358.

32. Koh MY, Spivak-Kroizman T, Venturini S, Welsh S, Williams RR, Kirkpatrick DL, et al. Molecular mechanisms for the activity of PX-478, an antitumor inhibitor of the hypoxia-inducible factor-1. Mol Cancer Ther. 2008:7:90-100.

33. Ziello JE, Jovin IS, Huang Y. Hypoxia-Inducible Factor (HIF)-1 regulatory pathway and its potential for therapeutic intervention in malignancy and ischemia. Yale Journal of Biology and Medicine. 2007;80(2):51-60.

34. Liew SY, Stanbridge EJ, Yusoff K, Shafee N. Hypoxia affects cellular responses to plant extracts. J Ethnopharmacol. 2012;144(2):453-6. https:// doi.org/10.1016/j.jep.2012.09.024

35. Cairns RA, Harris IS, MakTW. Regulation of cancer cell metabolism. Nature Reviews Cancer. 2011;11(2):85-95. https://doi.org/10.1038/nrc2981.

36. Fujimoto Y, Usui S, Making M, Sumatra M. Phloroglucinols from Baeckea frutescens. Phytochemistry. 1996;41:923-5.

37. Chen F, Zhuang $X$, Lin L, Yu P, Wang Y, Shi Y, et al. New horizons in tumor microenvironment biology: Challenges and opportunities. BMC Medicine. 2015;13:45. https://doi.org/10.1186/s12916-015-0278-7.

38. Roma-Rodrigues C, Mendes R, Baptista PV, Fernandes AR. Targeting tumor microenvironment for cancer therapy. International Journal of Molecular Sciences. 2019:20(4):840. https://doi.org/10.3390/ijms20040840.

39. Özdemir BC, Pentcheva-Hoang T, Carstens JL, Zheng X, Wu CC, Simpson $T R$, et al. Depletion of Carcinoma associated Fibroblasts and Fibrosis Induces Immunosuppression and Accelerates Pancreas Cancer with Reduced Survival. Cancer Cell. 2014;25:719-734. https://doi.org/10.1016/j. ccr.2014.04.005

40. Rhim AD, Oberstein PE, Thomas DH, Mirek ET, Palermo CF, Sastra SA, et al. Stromal elements act to restrain, rather than support, pancreatic ductal adenocarcinoma. Cancer Cell. 2014;25(6):735-47. https://doi.org/10. 1016/j.ccr.2014.04.021.

\section{Publisher's Note}

Springer Nature remains neutral with regard to jurisdictional claims in published maps and institutional affiliations.

Ready to submit your research? Choose BMC and benefit from:

- fast, convenient online submission

- thorough peer review by experienced researchers in your field

- rapid publication on acceptance

- support for research data, including large and complex data types

- gold Open Access which fosters wider collaboration and increased citations

- maximum visibility for your research: over 100M website views per year

At BMC, research is always in progress.

Learn more biomedcentral.com/submissions 